\title{
Clinical effectiveness of omental transposition in facilitating perineal wound healing after abdominoperineal resection: a systematic review
}

\author{
Sungjin Kim ${ }^{1}$, Sung Il Kang ${ }^{2}$, Sohyun Kim ${ }^{2}$, Jae Hwang Kim ${ }^{2}$ \\ ${ }^{1}$ Department of Surgery, Yeungnam University Hospital, Daegu, Korea \\ ${ }^{2}$ Department of Surgery, Yeungnam University College of Medicine, Daegu, Korea
}

Received: December 14, 2020

Revised: December 16, 2020

Accepted: January 13, 2021

Corresponding author:

Sung II Kang, MD

Department of Surgery, Yeungnam University College of Medicine, 170 Hyeonchung-ro, Nam-gu, Daegu 42415, Korea

Tel: +82-53-620-3580

Fax: +82-31-787-4055

E-mail:sungiry@naver.com
Background: Omental transposition has been used to facilitate perineal wound healing in patients undergoing abdominoperineal resection (APR). However, there is no high-level evidence supporting the effectiveness of omental transposition in this regard. This study aimed to investigate the clinical efficacy of omental transposition in facilitating perineal wound healing after APR.

Methods: In this systematic review, we systematically searched the PubMed/MEDLINE, Embase, Scopus, Cochrane Library, and Web of Science databases for literature regarding the topic of our study. Studies published since the inception of each database were considered for review. The outcomes of interest were the perineal wound healing rate at 1 and 3 months postoperatively, perineal wound infection rate, and perineal wound healing period.

Results: Of the 1,923 studies identified, four articles representing 819 patients (omental transposition patients, $n=295$ ) were included in the final analysis. The wound healing rates at 1 and 3 months postoperatively in the omental transposition group (68.5\% and $79.7 \%$, respectively) did not significantly differ from those in the control group ( $57.4 \%$ and $78.7 \%$, respectively) ( $p=0.759$ and $p=0.731$, respectively). Perineal wound infection and chronic wound complication rates, including sinus, dehiscence, and fistula rates, also did not significantly differ between the omental transposition ( $8 \%$ and $7 \%$, respectively) and control ( $11 \%$ and $7 \%$, respectively) groups ( $p=0.221$ and $p=0.790$, respectively).

Conclusion: Our results suggest that omental transposition does not affect perineal wound healing in patients who undergo APR.

Keywords: Abdominoperineal resection; Omental transposition; Perineal wound; Wound healing

\section{Introduction}

Since abdominoperineal resection (APR) was first introduced by Miles [1] nearly a century ago, it has been an important surgical method for refractory anorectal diseases, including low rectal cancer, select anal cancer, and inflammatory bowel disease [2,3]. Although the number of patients requiring APR has decreased with the advancement of medical devices and surgical techniques, almost $20 \%$ of all patients with low rectal cancer require APR.

Delayed perineal wound healing and perineal wound complications are the most common post-APR complications. The rates of perineal wound complications following APR and delayed perineal wound healing over 6 months have been reported to be as high

Copyright (C) 2021 Yeungnam University College of Medicine

This is an Open Access article distributed under the terms of the Creative Commons Attribution Non-Commercial License (http://creativecommons.org/licenses/by-nc/4.0/) which permits unrestricted non-commercial use, distribution, and reproduction in any medium, provided the original work is properly cited. 
as 50\% [4-7] and $25 \%$ [8], respectively. The high rate of perineal wound complications increases the length of hospital stay, readmission rates, and medical costs $[9,10]$. Several possible explanations include the formation of dead space in the presacral area after rectal resection and accumulation of fluids in the dead space, tension in the approximated perineum due to rigid side walls, and bacterial contamination originating from fecal material [8,11].

Surgeons have developed several techniques to reduce the rate of perineal wound complications, including the use of omental pedicles $[2,11,12]$, local antibiotics [13], negative pressure wound management devices [14], and mucocutaneous flaps [11]. However, omental transposition is the easiest technique to perform and requires no additional cost. The omentum is considered the "policeman of the abdomen" because it consists of fatty tissue that plays a key role in resisting infection. Additionally, its fatty tissue and apron-like appearance allow for easy mobilization into the pelvis and filling of the presacral dead space [2,9] (Fig. 1).

However, there is no high-level evidence regarding the effectiveness of omental transposition in facilitating perineal wound healing because almost all related studies have been retrospective and have had small sample sizes. Therefore, this study aimed to investigate the clinical efficacy of omental transposition in facilitating perineal wound healing after APR.

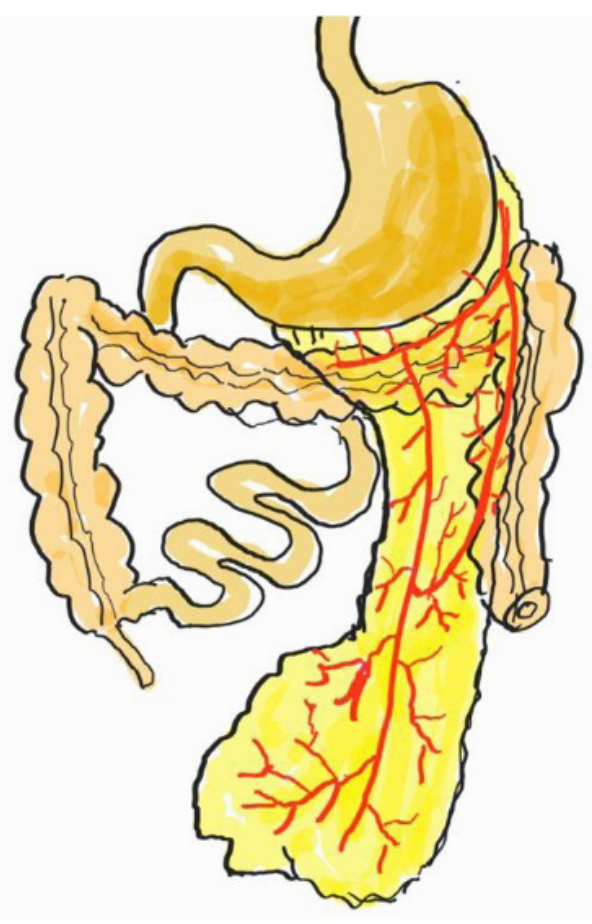

Fig. 1. Schematic picture of omental transposition.

\section{Materials and methods}

\section{Study design and literature search}

In this systematic review, we systematically searched the PubMed/ MEDLINE, Embase, Scopus, Cochrane Library, and Web of Science databases for literature. Studies published between the inception of each database, the earliest date being January 1, 1970, and May 9, 2018, were considered for review. This systematic literature search was conducted in accordance with the guidelines of the Preferred Reporting Items for Systematic Reviews and Meta-Analyses (PRISMA) [15]. The keywords used for the literature search were as follows: "omental transposition," "omental flap," "omental flap transposition," "omental pedicle flap," "omentopexy," "omentoplasty," "abdominoperineal resection," "APR," "abdominoperineal excision," "proctectomy," “coloproctectomy," "Miles' operation," "wound infection," "perineal wound infection," "wound complication," and "perineal wound complication."

Two authors independently selected eligible studies from the databases by reviewing the titles and abstracts of the studies. If there was a disagreement between reviewers concerning study eligibility, they discussed it until reaching a consensus. If necessary, an independent third author was involved in the discussion.

\section{Selection and exclusion criteria}

Only original articles and clinical studies, including case-control, cross-sectional, and cohort studies that investigated the efficacy of omental transposition in facilitating perineal wound healing were included in this review. No language restriction was applied. Studies were excluded if perineal wound-related morbidities were not reported, and if they did not report on comparable groups with omental transposition. Studies that were published as complete academic papers in peer-reviewed journals, while only presenting an abstract were also excluded. If we identified duplicate studies or multiple studies that presented data from the same source, the study that was published first was considered for review.

\section{Measured outcomes}

The primary outcomes of this study were the perineal wound healing rates at 1 and 3 months postsurgery. Secondary outcomes were the perineal wound healing period, length of hospital stay, and perineal wound infection rate. Subgroup analyses were permitted if data for secondary outcomes could be extracted from more than two articles among the included studies. 


\section{Results}

\section{Study inclusion}

Our literature search yielded 1,923 studies. Of these, 144 duplicate articles were excluded. After the remaining 1,757 articles were screened based on their titles and abstracts, only 22 articles were selected for a full-text review. After full-text review, 18 articles were excluded. Thus, four articles representing a total of 819 patients were included in the final analysis $[8,16-18]$. Fig. 2 pro- vides a PRISMA flow chart that outlines the article selection process.

\section{General characteristics of the included studies}

Of the four included studies, three were from Europe (France, the Netherlands, and Switzerland) and one was from Taiwan. Additionally, three were retrospective studies, and one was a prospective, multicenter, non-randomized study. Of the 819 patients, 295 (36.0\%) underwent omental transposition, and 549 (67.0\%) were

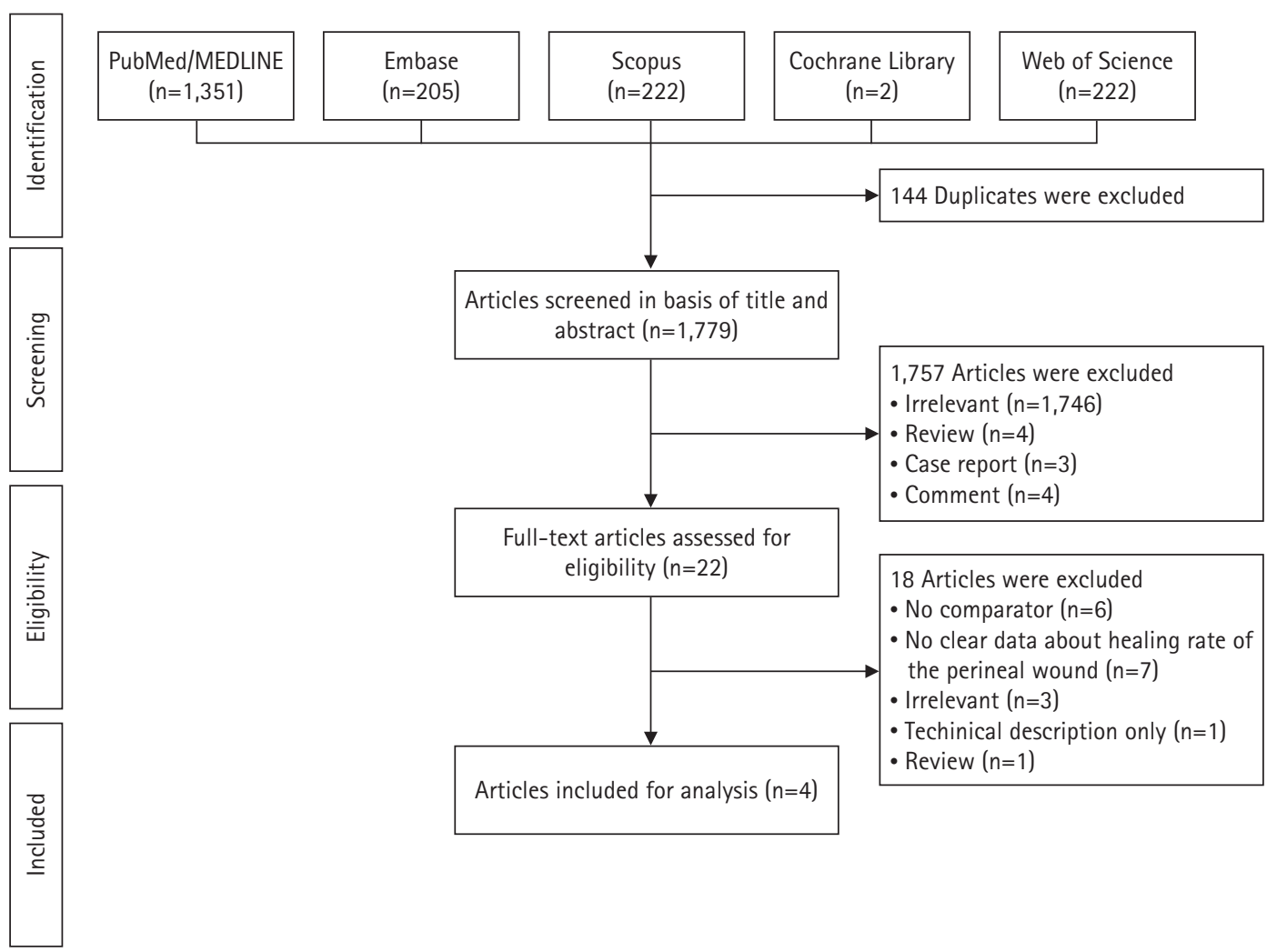

Fig. 2. Preferred Reporting Items for Systematic Reviews and Meta-Analyses (PRISMA) flow chart.

Table 1. Summarization of the four including studies

\begin{tabular}{|c|c|c|c|c|c|c|c|c|c|}
\hline Study & Year & Country & Type of study & $\begin{array}{l}\text { Mean } \\
\text { age (yr) }\end{array}$ & $\begin{array}{c}\text { Sex } \\
\text { (male: } \\
\text { female) }\end{array}$ & Disease (n) & $\begin{array}{c}\text { Omental } \\
\text { transposition (n) }\end{array}$ & Control (n) & Major measured outcome \\
\hline $\begin{array}{l}\text { John and } \\
\text { Buchmann [8] }\end{array}$ & 1991 & Switzerland & Retrospective & 63 & $44: 30$ & $\begin{array}{l}\text { Malignancy (71), } \\
\text { benign (3) }\end{array}$ & 38 & 36 & $\begin{array}{l}\text { Delayed wound healing, influence } \\
\text { on perineal wound healing by } \\
\text { grafted omentum }\end{array}$ \\
\hline Wang et al. [16] & 1994 & Taiwan & Retrospective & 56.7 & 49:33 & $\begin{array}{l}\text { Malignancy (83), } \\
\text { benign (0) }\end{array}$ & 21 & $82^{\text {a) }}$ & $\begin{array}{l}\text { Healing of the wound, } \\
\text { postoperative complication }\end{array}$ \\
\hline Hay et al. [17] & 1997 & France & Prospective & 64 & $101: 64$ & $\begin{array}{l}\text { Malignancy (165), } \\
\text { benign (0) }\end{array}$ & 64 & 101 & $\begin{array}{l}\text { The number of healed perineums } \\
\text { at } 1 \text { month, time to complete } \\
\text { primary healing }\end{array}$ \\
\hline Blok et al. [18] & 2018 & Netherlands & Retrospective & 67 & $332: 145$ & $\begin{array}{l}\text { Malignancy (477), } \\
\text { benign (0) }\end{array}$ & 172 & 305 & $\begin{array}{l}\text { Non-healing rate of the perineal } \\
\text { wound, 30-day mortality/ } \\
\text { complication/readmission }\end{array}$ \\
\hline
\end{tabular}

a) Sum of the three control groups: suture of the pelvic perineum with open drainage $(n=20)$, suture of the pelvic perineum and perineum with simple drainage $(n=30)$, and suture of the pelvic peritoneum and perineum with suction drainage $(n=32)$. 
Table 2. The rate of perineal wound healing at 1 and 3 months

\begin{tabular}{|c|c|c|c|c|c|c|}
\hline \multirow{2}{*}{ Study } & \multicolumn{3}{|c|}{ One month after operation } & \multicolumn{3}{|c|}{ Three months after operation } \\
\hline & Omental transposition & Control & $p$-value & Omental transposition & Control & $p$-value \\
\hline John and Buchmann [8] & 19/38 (50.0) & $15 / 36(41.7)$ & 0.298 & $33 / 38(86.8)$ & $25 / 36(69.4)$ & 0.069 \\
\hline Wang et al. [16] & $19 / 21(90.5)$ & $59 / 82(72.0)$ & 0.077 & $21 / 21(100)$ & $75 / 82(91.5)$ & 0.340 \\
\hline Hay et al. [17] & $42 / 62(67.7)$ & $67 / 99(67.7)$ & 0.993 & $53 / 61(86.9)$ & 77/94 (81.9) & 0.588 \\
\hline Blok et al. [18] & $80 / 152(52.6)$ & $140 / 272(51.5)$ & 0.819 & $110 / 152(72.4)$ & $204 / 272(75.0)$ & 0.553 \\
\hline Total & $160 / 273(58.6)$ & $281 / 489(57.5)$ & 0.759 & $217 / 272(79.8)$ & $381 / 484$ (78.7) & 0.731 \\
\hline
\end{tabular}

Values are presented as number (\%).

Table 3. Wound healing period, perineal wound infection, and hospital stay

\begin{tabular}{|c|c|c|c|c|c|c|c|}
\hline \multirow{2}{*}{ Study } & \multicolumn{2}{|c|}{ Mean wound healing period (day) } & \multicolumn{3}{|c|}{ Perineal wound infection } & \multicolumn{2}{|c|}{ Mean hospital stay (day) } \\
\hline & Omental transposition & Control & Omental transposition & Control & $p$-value & Omental transposition & Control \\
\hline John and Buchmann [8] & 33 & 85 & $13 / 64(20.3)$ & 22/101 (21.8) & & 21 & 22 \\
\hline Wang et al. [16] & NR & NR & $6 / 172(3.5)$ & $11 / 305(3.6)$ & & NR & NR \\
\hline Hay et al. [17] & 20 & 20 & $4 / 21(19.0)$ & 25/82 (30.5) & & 22 & 25 \\
\hline Blok et al. [18] & NR & NR & NR & NR & & 31 & 28 \\
\hline Total & & & 23/257 (8.9) & $58 / 488(11.9)$ & 0.221 & & \\
\hline
\end{tabular}

Values are presented as number only or number (\%).

$\mathrm{NR}$, not reported.

males. Most patients underwent surgery for malignancy, except for three patients who had inflammatory bowel disease. The characteristics of the included studies are summarized in Table 1.

\section{Perineal wound healing rate}

Table 2 shows the rate of perineal wound healing at 1 and 3 months postsurgery. All four studies revealed no significant differences in perineal wound healing rates between the omental transposition and control groups at 1 and 3 months postsurgery. The mean perineal wound healing rate at one month postsurgery was $58.6 \%$ in the omental transposition group and $57.4 \%$ in the control group $(p=0.759)$. The mean perineal wound healing rate at 3 months postsurgery was $79.7 \%$ in the omental group and $78.7 \%$ in the control group $(p=0.731)$.

\section{Perineal wound healing period, perineal wound infection rate, and length of hospital stay}

Of the four included studies, two presented data regarding the perineal wound healing period, three presented data regarding perineal wound infection rates, and three presented data regarding the length of hospital stay (Table 3). In one study, the omental transposition group required significantly fewer days to achieve perineal wound healing than the control group. However, another study reported no significant differences between the two groups in this regard. Additionally, two studies reported no significant differences in the perineal wound infection rates between the two groups. However, one study showed that perineal wound infection rates were lower in the omental transposition group than in the control group, but the sum of the infection rates was not significantly different between the two groups. Lastly, three studies reported that the mean hospital stay and mean length of hospital stay did not significantly differ between the two groups.

\section{Discussion}

Perineal wound complications are one of the main causes of postAPR morbidity and discomfort. In the early period after the introduction of APR, perineal wounds were opened with packing after the operation, or the perineal skin was loosely approximated with the drain inserted [19]. This method was previously used for perineal wound management because it was believed that perineal wound healing via primary closure was impossible due to the large dead space formed after APR. However, this traditional method can cause considerable discomfort to patients and prolonged hospitalization periods. Therefore, many authors have proposed methods for the primary closure of perineal wounds in order to achieve favorable results $[20,21]$. However, despite these reports, the incidence of failed healing in closed perineal wounds remains high [21]. It is believed that fluid or blood clots may be collected in the postsurgical dead space, thereby causing pelvic and perineal sepsis, abscess formation, and delayed wound healing.

To prevent fluid collection in the presacral dead space, surgeons have attempted to fill the dead space with omental pedicle grafts [22]. Studies have shown that omental transposition reduces the 
number of infectious post-APR complications, and recent systematic reviews have reported that it reduces perineal wound morbidity rates $[8,17,23]$. Additionally, omental transposition improves antibiotic delivery and local immunity by promoting angiogenesis, thereby preventing secondary infections [24]. Furthermore, omental pedicles are expected to prevent the small bowel from descending into the pelvic cavity, thereby reducing the risk of ileus.

However, contrary to previous reports and posited mechanisms for preventing failed/delayed wound healing, our systematic review showed that omental transposition did not improve perineal wound healing in APR patients. Omental transposition techniques have several limitations. For instance, mobilization of the great omentum requires additional abdominal incisions [25], and the operation time has been reported to be 15 to 20 minutes more [26]. Moreover, omental transposition-related morbidities, including omentum necrosis caused by compromised perfusions [27], local discharge associated with partial necrosis [28], and obstruction due to adhesion or band [29], have also been reported. Additionally, if the size of the omentum is insufficient to fill the pelvic cavity, fluid collection and abscess formation can occur because of the presence of residual cavities.

In a recently published meta-analysis, it was found that omental transposition had no effect on wound healing [30]. Moreover, this meta-analysis reported omental transposition-related complications. However, unlike our study, the meta-analysis' outcomes included wound healing and postomental transposition complications, such as perineal hernias, ileus, and omental flaps. They reported that the incidence of perineal hernias significantly increased due to omental transposition. Theoretically, omenta with long vascular pedicles descend further than small bowel loops, which are limited in their descent by the mesentery length. Therefore, fatty and non-fibrous omenta may cause hernias, as they apply constant pressure on the perineal skin while patients remain in the standing position.

This study had several limitations. First, the definitions of outcome variables in the included studies were inconsistent, and some outcomes, such as perineal wound healing and wound infection, were not consistently reported in each study. Second, since our outcomes were limited to wound healing and wound infection, our review only included four studies. Therefore, the number of patients included in the omental transposition and control groups was small. Third, since there was no control for certain variables, such as patient demographics and the American Society of Anesthesiologists status, correction for population heterogeneity was not performed. Fourth, of the four studies included in this review, three were conducted before the year 2000. The development of perioperative surgical and oncological practices was remarkable during this period, and it is likely that different surgical and oncological approaches were used. Lastly, the main limitation of our study was the possibility of allocation bias. Surgeons may have adapted omental transposition for patients with the potential for large presacral spaces in studies that did not involve randomized controlled trials. As such, it is possible that wound complications occurred more frequently in the omental transposition group.

In conclusion, this systematic review reveals that omental transposition does not have a beneficial effect on perineal wound healing in after APR.

\section{Notes}

\section{Conflicts of interest}

No potential conflict of interest relevant to this article was reported.

\section{Author contributions}

Conceptualization: Sungjin K, SIK, Sohyun K, JHK; Data curation: SIK, Sohyun K; Formal analysis: Sungjin K, SIK, JHK; Methodology: Sungjin K; Project administration, Software, Supervision: SIK; Visualization: Sohyun K; Investigation: Sungjin K, SIK, Sohyun K, JHK; Resources: Sungjin K; Validation: Sohyun $\mathrm{K}$, JHK; Writing - original draft: Sungjin K; Writing - review \& editing: Sungjin K, SIK, Sohyun K, JHK.

\section{ORCID}

Sungjin Kim, https://orcid.org/0000-0002-3773-3799

Sung Il Kang, https://orcid.org/0000-0002-4751-5779

Sohyun Kim, https://orcid.org/0000-0002-8625-329X

Jae Hwang Kim, https://orcid.org/0000-0002-8556-6315

\section{References}

1. Miles WE. A method of performing abdomino-perineal excision for carcinoma of the rectum and of the terminal portion of the pelvic colon (1908). CA Cancer J Clin 1971;21:361-4.

2. Nilsson PJ. Omentoplasty in abdominoperineal resection: a review of the literature using a systematic approach. Dis Colon Rectum 2006;49:1354-61.

3. Mohammed S, Anaya DA, Awad SS, Albo D, Berger DH, Artinyan A. Sphincter preservation rates after radical resection for rectal cancer in the United States veteran population: opportunity for improvement in early disease. Ann Surg Oncol 2015; 22:216-23. 
4. Tompkins RG, Warshaw AL. Improved management of the perineal wound after proctectomy. Ann Surg 1985;202:760-5.

5. Fingerhut A, Hay JM, Delalande JP, Paquet JC. Passive vs. closed suction drainage after perineal wound closure following abdominoperineal rectal excision for carcinoma. A multicenter, controlled trial. The French Association for Surgical Research. Dis Colon Rectum 1995;38:926-32.

6. Artioukh DY, Smith RA, Gokul K. Risk factors for impaired healing of the perineal wound after abdominoperineal resection of rectum for carcinoma. Colorectal Dis 2007;9:362-7.

7. Musters GD, Sloothaak DA, Roodbeen S, van Geloven AA, Bemelman WA, Tanis PJ. Perineal wound healing after abdominoperineal resection for rectal cancer: a two-centre experience in the era of intensified oncological treatment. Int J Colorectal Dis 2014;29:1151-7.

8. John H, Buchmann P. Improved perineal wound healing with the omental pedicle graft after rectal excision. Int J Colorectal Dis 1991;6:193-6.

9. Wiatrek RL, Thomas JS, Papaconstantinou HT. Perineal wound complications after abdominoperineal resection. Clin Colon Rectal Surg 2008;21:76-85.

10. El-Gazzaz G, Kiran RP, Lavery I. Wound complications in rectal cancer patients undergoing primary closure of the perineal wound after abdominoperineal resection. Dis Colon Rectum 2009;52:1962-6.

11. Nisar PJ, Scott HJ. Myocutaneous flap reconstruction of the pelvis after abdominoperineal excision. Colorectal Dis 2009; 11:806-16.

12. Hultman CS, Sherrill MA, Halvorson EG, Lee CN, Boggess JF, Meyers $\mathrm{MO}$, et al. Utility of the omentum in pelvic floor reconstruction following resection of anorectal malignancy: patient selection, technical caveats, and clinical outcomes. Ann Plast Surg 2010;64:559-62.

13. de Bruin AF, Gosselink MP, Wijffels NA, Coene PP, van der Harst E. Local gentamicin reduces perineal wound infection after radiotherapy and abdominoperineal resection. Tech Coloproctol 2008; $12: 303-7$.

14. Sumrien H, Newman P, Burt C, McCarthy K, Dixon A, Pullyblank A, et al. The use of a negative pressure wound management system in perineal wound closure after extralevator abdominoperineal excision (ELAPE) for low rectal cancer. Tech Coloproctol 2016;20:627-31.

15. Liberati A, Altman DG, TetzlaffJ, Mulrow C, Gøtzsche PC, Ioannidis JP, et al. The PRISMA statement for reporting systematic reviews and meta-analyses of studies that evaluate health care interventions: explanation and elaboration. PLoS Med 2009; 6:e1000100.
16. Wang JY, Huang CJ, Hsieh JS, Huang YS, Juang YF, Huang TJ. Management of the perineal wounds following excision of the rectum for malignancy. Gaoxiong Yi Xue Ke Xue Za Zhi 1994; 10:177-81.

17. Hay JM, Fingerhut A, Paquet JC, Flamant Y. Management of the pelvic space with or without omentoplasty after abdominoperineal resection for carcinoma of the rectum: a prospective multicenter study. The French Association for Surgical Research. Eur J Surg 1997;163:199-206.

18. Blok RD, Musters GD, Borstlap WA, Buskens CJ, Bemelman WA, Tanis PJ, et al. Snapshot study on the value of omentoplasty in abdominoperineal resection with primary perineal closure for rectal cancer. Ann Surg Oncol 2018;25:729-36.

19. Miles WE. Technique of the radical operation for cancer of the rectum. Br J Surg 1914;2:292-305.

20. Oates GD, Williams JA. Primary closure of the perineal wound in excision of the rectum. Proc R Soc Med 1970;63(Suppl 1): 128 .

21. Broader JH, Masselink BA, Oates GD, Alexander-Williams J. Management of the pelvic space after proctectomy. Br J Surg 1974;61:94-7.

22. Ruckley CV, Smith AN, Balfour TW. Perineal closure by omental graft. Surg Gynecol Obstet 1970;131:300-2.

23. Killeen S, Devaney A, Mannion M, Martin ST, Winter DC. Omental pedicle flaps following proctectomy: a systematic review. Colorectal Dis 2013; 15:e634-45.

24. Collins D, Hogan AM, O'Shea D, Winter DC. The omentum: anatomical, metabolic, and surgical aspects. J Gastrointest Surg 2009;13:1138-46.

25. Moreaux J, Horiot A, Barrat F, Mabille J. Obliteration of the pelvic space with pedicled omentum after excision of the rectum for cancer. Am J Surg 1984;148:640-4.

26. Smith SR, Swift I, Gompertz H, Baker WN. Abdominoperineal and anterior resection of the rectum with retrocolic omentoplasty and no drainage. BrJ Surg 1988;75:1012-5.

27. Marks CG, Leighton M, Ritchie JK, Hawley PR. Primary suture of the perineal wound following rectal excision for adenocarcinoma. Br J Surg 1976;63:322-6.

28. Dencker H, Norryd C, Tranberg KG. Management of the perineal wound after rectal excision. Acta Chir Scand 1973;139: 568-70.

29. Ferguson CM. Use of omental pedicle grafts in abdominoperineal resection. Am Surg 1990;56:310-2.

30. Blok RD, Hagemans JA, Klaver CE, Hellinga J, van Etten B, Burger JW, et al. A systematic review and meta-analysis on omentoplasty for the management of abdominoperineal defects in patients treated for cancer. Ann Surg 2020;271:654-62. 